\title{
Early isolation in the gerbil (Meriones unguiculatus): Behavioral and physiological effects
}

\author{
RICHARD A. BERG, RICHARD D. SHANIN, and ELAINE M. HULL \\ State University of New York at Buffalo, Buffalo, New York 14226
}

\begin{abstract}
Gerbils were reared from Day 15 to Day 170, either in social and perceptual isolation or with nonlactating foster parents and foster siblings. Territorial marking, aggression, and open-field activity were markedly depressed by the isolation conditions. Spontaneous seizures were observed in every isolated animal during testing, but only occasionally in control animals. Adrenal glands of isolates were heavier. Body, ventral gland, and testes weights were not affected by the experimental conditions.
\end{abstract}

Most studies of isolation have found that it results in increased aggressiveness and/or emotionality (Bannerjee, 1971; Hatch, Wiberg, Balaza, \& Grice, 1963; Hull, Rosselli, \& Langan, 1973; Korn \& Moyer, 1968; Scott, 1966; Valzelli, 1969). Also, isolated animals typically exhibit heavier adrenal glands (Geller, Yuwiler, \& Zolman, 1965; Hatch et al., 1963) and increased activity levels compared with grouped animals (Bell, Miller, Ordy, \& Rolsten, 1971; Bronson, 1963; Levitsky \& Barnes, 1972; and Wodzicki \& Roberts, 1960), although there are conflicting reports (Brain \& Nowell, 1970; Bronson, 1963; Christian, 1955; Meyers \& Fox, 1963; Rodgers \& Thiessen, 1964). Furthermore, discrepancies have been reported in the effects of grouping vs. isolation on measures of "sociability." In some cases, isolated rats were reported to be more "gregarious" (Casey, 1962; Latané, Cappell, \& Joy, 1970; Shelley \& Hoyenga, 1967), while in other cases, less so (Angermeier, 1959; Ashida, 1964).

Most of the above experiments have utilized an isolation procedure instituted either at weaning or at an appreciable time after weaning. In a few studies, rodents have been isolated either at birth or shortly thereafter, and their subsequent adult sexual behavior and/or social approaches to a test animal were observed. The major findings are that very early isolation, even in the precocial guinea pig, disrupts the ability to engage in appropriate sexual behavior when the animal matures (Beauchamp \& Hess, 1973; Gerall, 1963). However, Harper (1968) found that guinea pigs isolated at birth exhibited a greater tendency to contact a strange test animal than did nonisolated animals. Since rats and most other rodents are altricial, it is more difficult to isolate them very early. However, Gruendel and Arnold (1969) developed an incubator in which day-old rat pups could

This experiment was submitted in partial fulfillment of requirements for the undergraduate Psychology Honors program by the first author and Independent Study requirements by the second author. It was supervised by the third author. Reprint requests should be sent to Elaine $M$. Hull, Department of Psychology, SUNY at Buffalo, 4230 Ridge Lea Road, Buffalo, New York 14226 . be housed. They found that only animals reared with their mothers were able to copulate properly and to ejaculate as adults. There were no differences in time spent with the test female. These studies indicate that important components of sexual behavior must be learned and that early isolation renders the adult animal incapable of performing properly.

The ability of isolation to enhance aggressiveness is also a function of age at initiation of isolation and conditions. Senault (1971) found that young rats isolated for 2 months after weaning showed enhanced apomorphine-induced aggression if housed in wire netting cages, but not if housed in opaque boxes. Adults, however, exhibited enhanced apomorphine-induced aggression if isolated in either condition, but especially in the opaque boxes. Again, it would seem that visual contact with other animals is critical at a certain stage of life in order for the adult pattern of behavior to occur. Furthermore, Hull, Rosselli, and Langan (1973) found that isolation immediately after weaning in opaque metal cages led to increased aggressiveness in guinea pigs, but similar conditions of isolation initiated in adults did not enhance fighting behavior. The differing results would appear to be due to difference in species or experimental or test conditions.

The present experiment was designed to test a broad range of effects of early isolation in gerbils. Gerbils were chosen because their territorial marking is easily observed and is the topic of a number of recent investigations (Thiessen, Lindzey, Blum, \& Wallace, 1970; Thiessen, Yahr, \& Owen, 1973), because they have a repertoire of interesting and relatively natural behavior patterns and because the effects of isolation after weaning in these animals have already been investigated (Hull et al., 1973). Gerbils were removed from their home cages at 15 days of age. (Normal weaning age for gerbils is 28 days.) They were then placed into either isolation cages or with nonlactating foster parents and foster siblings. At adulthood they were tested on several social, territorial, and physiological measures. 
Table 1

Open-Field Measures for 10-Min Period

\begin{tabular}{lccrrr}
\hline & \multicolumn{2}{c}{ Activity } & & \multicolumn{2}{c}{ Marking } \\
\cline { 2 - 3 } \cline { 5 - 6 } Group & Mean & SD & & Mean & SD \\
\hline Isolate Male & 168.00 & 93.16 & 2.33 & 4.35 \\
Isolate Female & 233.25 & 85.87 & .12 & .32 \\
Control Male & 320.80 & 34.52 & 6.40 & 3.72 \\
Control Female & 299.89 & 85.87 & 5.40 & 8.69 \\
\hline
\end{tabular}

\section{METHOD}

\section{Subjects}

Twenty-eight Mongolian gerbils (Meriones unguiculatus) weto obtained from the gerbil colony of the Psychology Department at SUNY at Buffalo. They were separated from parents and siblings within $30 \mathrm{~h}$ of 15 days of age. (Of 31 animals originally obtained, 2 in the control group died from unknown causes, as did one in the experimental group which had been isolated at 14 days of age.)

\section{Apparatus}

The open-field apparatus, used for both open-field and social interaction tests was $1 \mathrm{~m}^{2}$, painted gray, and lined off into 16 squares of equal size. Clear-plastic dowels, $2 \mathrm{~cm}$ long, were inserted into holes at the corners of the 16 squares except at the edges of the field. The sides of the apparatus were $48.0 \mathrm{~cm}$ high and were hinged at the middle.

\section{Procedure}

Experimental conditions. The animals were randomly assigned to two groups of 15 isolates and 13 controls. The control animals were placed into standard clear-plastic cages $(23 \times 45 \times 15 \mathrm{~cm})$ with nonlactating foster parents and other control pups. One cage contained four control animals and three other cages contained three control animals each, in addition to the foster parents. The control pups were initially separated from the foster parents by means of a wire mesh divider placed in the cage for $24 \mathrm{~h}$ so that the foster parents could become familiar with their new offspring without attacking them. The experimental group was placed in isolation upon separation from their parents and siblings. Each gerbil in the isolate group was placed into a plastic cage painted flat black and measuring $28 \times 18 \times 12.5 \mathrm{~cm}$. Each cage was fitted with a cover constructed of wood and clear plastic. Two holes in each of the fitted tops served as air inlets, and air was removed through plastic tubes which ran in front of an exhaust fan. The forced-air system minimized olfactory communication among animals and also provided an auditory masking noise. Isolated gerbils were handled once per week for cage cleaning, food and water replenishment, and weighing.

Behavioral testing. Beginning at 170 days of age, the animals were tested for exploratory activity and territorial marking in the open field. The animals were placed singly into the apparatus and observed for 10 min during which time number of ventral rubs on either a peg or the floor, number of squares entered with all four feet, number of escape attempts, and time spent in convulsive seizure activity or freezing behavior were recorded. After the animal was removed, the number of pools of urine and of fecal boluses were also counted and recorded. The floor, walls, and dowels of the field were washed after each test with a dilute ethyl alcohol solution.

After all open field tests had been completed, each animal was tested for social interaction and marking. Each animal was paired first with another animal in the same housing condition but from a different cage, and on a subsequent day with an animal from the opposite housing condition. Each pair was marked on the back of the head with different colored felt tipped pens and was allowed to interact in the open field apparatus for $10 \mathrm{~min}$. The experimenter judging the behavior did not know which condition the animals were from. Each time an animal initiated fighting, boxing, chasing, pushing, sniffing and/or nonaggressive contact, exhibited ventral gland marking, or attempted to escape from the apparatus, the appropriate category was checked. The duration and instances of convulsive seizure and freezing behavior were also recorded. If both animals initiated an activity simultaneously, both were credited with the action. After each test, the apparatus was cleaned with a dilute alcohol solution.

Atter completion of the behavioral testing, the animals were sacrificed by means of ether inhalation. Age at the time of sacrifice was approximately 205 days. Body weights were recorded to the nearest 10 th of a gram; adrenal-gland weights, testes weights, and ventral-gland weights were measured to the nearest milligram.

\section{RESULTS}

Control animals were significantly more active than were isolated animals $(\mathrm{F}=7.84, \mathrm{df}=1 / 26, \mathrm{p}<.01)$ (see Table 1). Furthermore, recomputation of activity during time not engaged in seizures indicated that activity of isolates was still less than that of controls $(F=6.75$, $\mathrm{df}=1 / 26, \mathrm{p}<.05$ ). Control animals also engaged in more ventral gland marking than did isolates $(\mathrm{F}=5.29$, $\mathrm{df}=1 / 26, \mathrm{p}<.05)$. Isolated animals spent more time in seizure and/or freezing behavior than did the control animals $(F=4.84, d f=1 / 26, p<.05)$. Other measures showed no significant differences, and there were no significant differences between sexes.

Analysis of variance computed on a combined measure of aggression (all instances of fighting, chasing, boxing, and pushing) showed the control animals to be more aggressive than the isolated $(\mathrm{F}=9.98, \mathrm{df}=1 / 26$, $\mathrm{p}<.01$ ) (see Table 2). Control animals also marked

Table 2

Mean Social Interaction Scores in 10 Min

\begin{tabular}{|c|c|c|c|c|c|c|}
\hline \multirow[b]{2}{*}{ Group } & \multicolumn{2}{|c|}{$\begin{array}{l}\text { Seizure and/or } \\
\text { Freezing (Sec) }\end{array}$} & \multicolumn{2}{|c|}{ Marking } & \multicolumn{2}{|c|}{$\begin{array}{c}\text { Aggressive } \\
\text { Encounters }\end{array}$} \\
\hline & Mean & SD & Mean & SD & Mean & SD \\
\hline Isolate Male & 194.17 & 105.41 & 2.33 & 3.73 & 2.17 & 1.21 \\
\hline Isolate Female & 247.50 & 153.32 & 1.25 & 1.28 & 1.75 & 1.98 \\
\hline Control Male & 97.00 & 120.07 & 15.20 & 13.29 & 7.40 & 4.32 \\
\hline Control Female & 63.89 & 96.23 & 7.44 & 2.68 & 4.89 & 3.72 \\
\hline
\end{tabular}


significantly more than the isolates $(\mathrm{F}=8.45, \mathrm{df}=1 / 26$, $\mathrm{p}<.01)$. No other measure showed statistically significant differences, and sex differences were not significantly different on any of these measures.

Among the anatomical measures, only adrenal-gland weights showed a significant difference, with isolated animals having heavier adrenal glands than did controls $(\mathrm{F}=8.41, \mathrm{df}=1 / 26, \mathrm{p}<.01)$ (see Table 3). Differences in weight gain, final body weight, ventral-gland weights, and testes weights were not significant, nor were there any sex differences.

\section{DISCUSSION}

Isolation prior to the time of natural weaning in gerbils yields several results which are opposite of those generally obtained with later isolation of gerbils, rats, and guinea pigs. Perhaps the result which is most surprising is that in this study, isolated animals were much less aggressive than those animals raised in a relatively normal environment, while numerous other studies have reported that isolation leads to increased aggression. It is interesting that Senault (1971) found an increase in apomorphine-induced aggression in rats isolated shortly after weaning only if the animals were housed in wire netting cages, rather than in opaque boxes. Animals in this experiment were almost completely deprived of any form of social contact between 15 and 170 days of age. It would appear that some degree of social communication at this age may be necessary for the enhancement of aggression to occur, both in rats and in gerbils.

It was also surprising that control animals engaged in significantly more territorial marking than did isolates, both in the open-field and the social-interaction tests. Based on the previous work of Hull et al. (1973), Hull et al. (1974), and Thiessen et al. (1970), it was expected that territorial marking by isolated animals would be greater than that exhibited by control gerbils. Again, it would appear that some component of, or stimulus for, marking behavior must be learned and that learning occurs after 15 days of age. It was noted in the present experiment that few isolated animals which did exhibit some ventral marking were those that had been isolated latest. The deficits in marking and aggression in the present experiment appear similar to sexual deficits observed in early isolated rats (Gruendel \& Arnold, 1969) and guinea pigs (Beauchamp \& Hess, 1973; Gerall, 1963).

"Sociability," measured as number of sniffs and nonaggressive contacts, was not affected by the experimental conditions. This is in contrast with the enhancement of "sociability" by isolation found by Harper (1968) in guinea pigs and Casey (1962), Latané et al. (1970), and Shelly \& Hoyenga (1967) in rats, and with the decrease found by Angermeier (1959) and Ashida (1964) in rats.
Table 3

Average Adrenal Gland Weights in Milligrams

\begin{tabular}{lcc}
\hline & \multicolumn{2}{c}{ Adrenal Weights } \\
\cline { 2 - 3 } Group & Mean & SD \\
\hline Isolate Male & 32.55 & 5.10 \\
Isolate Female & 31.11 & 5.30 \\
Control Male & 25.59 & 4.80 \\
Control Female & 27.44 & 3.90 \\
\hline
\end{tabular}

Isolated animals consistently froze and experienced more seizures than did control animals during testing in the open-field apparatus. Upon first exposure to the apparatus, every isolate manifested a full convulsive seizure within $60 \mathrm{sec}$. Additional exposure to the apparatus during social interaction tests again led to convulsive seizure by all animals in the isolate group. However, this occurred only upon the initial physical contact with the other animal, and differences from controls in time spent in seizure and freezing were not statistically significant. Such seizures have been observed to occur in gerbils upon encountering a strange and/or stressful situation (Thiessen et al., 1968), and to increase in gerbils from the age of 2 months to about 6 months (Kaplan \& Miezcjeski, 1972). Also, Shreiber (1971) found that audiogenic seizures occurred more frequently in isolated than in grouped rats. If an animal is isolated from the vast majority of social and sensory stimuli which are normally a part of its environment, subsequent exposure to these stimuli all at once may result in far more sensory input than the animal is capable of dealing with effectively. This is suggestive of the hypersensitivity which follows denervation and, frequently, less drastic sensory deprivation. Thiessen et al. (1968), found that repeated daily exposure to the test conditions eliminated the seizures by the 4 th day. In the present experiment, time spent in seizures also decreased on later trials, as the animals became accustomed to the test situation.

The only anatomical measure which showed significant differences was that of adrenal-gland weight. Isolated animals had heavier adrenal glands than did the control animals. Thus, if adrenal weights are used as an index of stress (Christian, 1963), it would appear that long-term isolation, initiated early in life is more stressful than is group living. Hull et al. (1973) found that adrenals of males isolated at weaning were heavier than those of animals in medium-density samesex conditions (two or eight animals per 10-gal aquarium). The fact that females as well as males in the present experiment exhibited the adrenal hypertrophy may reflect the more stringent conditions of isolation here and/or the earlier onset of isolation.

It is not clear whether it was the lack of social contacts or the general sensory deprivation which led to the deficient behavior patterns observed. However, it is clear that early isolation in the gerbil gives rise to quite 
different behavior than does isolation at a later time. Both marking behavior and aggression, which are usually enhanced by isolation, were decreased here, suggesting the importance of learned components of both.

\section{REFERENCES}

Angermeier, W. F. Some basic aspects of social reinforcement in albino rats. Unpublished doctoral dissertation, University of Georgia, 1959.

Ashida, S. Modification by early experience of the tendency toward gregariousness in rats. Psvchoromic Scinnee, 1, 343-344.

Bannerjee, $U$. An inquiry inı the genesis of aggression in mice induced by isolation. Behaviour, 1971, XL, 86-97.

Beauchamp, G. K., \& Hess, E. H. Abnormal early rearing and sexual responsiveness in male guinea pigs. Journal of Comparative and Physiological Psychology, 1973, 85, 383-396.

Bell, R. W., Miller, C. E., Ordy, J. M., \& Rolsten, C. Effects of population density and living space upon neuroanatomy neurochemistry and behavior in the C57BL/10 mouse. Journal of Comparative and Physiological Psychology, 1971, 75, of Compar

Brain, P. F., \& Nowell, N. W. The effects of differential grouping on endocrine function of mature albino mice. Physiology and Behavior, 1970, 5, 907-910.

Bronson, F. H. Density, subordination, and social timidity in Peromyscus and C57 BL/10J mice. Animal Behavior, 1963, 11 475-479.

Casey, A. Gregarious behavior in the rat as a function of secondary reinforcement drive and novelty. Unpublished doctoral dissertation, University of Kansas. In Dissertation Abstracts International, 1962.

Christian, J. J. Effect of population size on the adrenal glands and reproductive organs of male mice in populations of fixed size. American Journal of Psychology, 1955, 182, 292-300.

Christian, J. J. Endocrine adaptive mechanisms and the physiologic regulation of population size. In W. Mayer and $R$ Van Gelder (Eds.), Physiological mammalogy Vol. 1. New York: Academic Press, 1963.

Gerall, A. A. An exploratory study of the effect of social isolation variables on the sexual behaviour of male guinea pigs. Animal Behaviour, 1963, 11, 247-282.

Geller, E. Yuwiler, A., \& Zolman, J. F. Effects of environmental complexity on constituents of brain and liver. Journal of Neurochemistry, 1965, 12, 949-955.

Gruendel, A. D., \& Arnold, W. J. Effects of early social deprivation on reproductive behavior of male rats. Journal of Comparative and Physiological Psychology, 1969, 67, 123-128.

Harper, L. V. The effects of isolation from birth on the social behavior of guinea pigs in adulthood. Animal Behavior, 1968 . $16,58-64$.

Hath A wiberg, G. S. Balaza, T., \& Grice, H. C. Long-term isolation stress in rats. Science, 1963, 142, 507

Hull, E. M., Hamilton, K. L., Engwall, D. B., \& Rosselli, L. Effects of olfactory bulbectomy and peripheral deafferentation on reactions to crowding in gerbils (Meriones unguiculatus). Journal of Comparative and Physiological Psychology, 1974, 86, 247-254.
Hull, E. M., Langan, C. J., \& Rosselli, L. Population density and social, territorial, and physiological measures in the gerbil (Meriones unguiculatus). Journal of Comparative and Physiological Psychology, 1973, 84, 414-422.

Hull, E. M., Rosselli, L., \& Langan, C. J. Effects of isolation and grouping on guinea pigs. Behavioral Biology, 1973, 9, 493-497.

Kaplan, H., \& Miezcjeski, C. Development of seizures in the Mongolian gerbil (Meriones unguiculatus). Journal of Comparative and Physiological Psychology, 1972, 81. 267-273.

Korn, J. H., \& Moyer, K. E. Behavioral effects of isolation in the rat: The role of sex and time of isolation. Journal of Genetic Psychology, 1968, 113, 263-273.

Latané, B., Cappell, H., \& Joy, V. Social deprivation, housing density, and gregariousness in rats. Journal of Comparative and Physiological Psychology, 1970, 70, 221-227.

Levitsky, D. A., \& Barnes, R. H. Nutritional and environmental interactions in the behavioral development of the rat: Long-term effects. Science, 1972, 176, 68-71.

Myers, D., \& Fox, J. Differences in maze performance of group vs. isolation reared rats. Psychological Reports, 1963, 12, 199-202.

Rodgers, D. A., \& Thiessen, D. D. Effects of population density on adrenal size, behavioral arousal, and alcohol preference on C3H/Crgl/2 inbred mice. Quarterly Journal for the Study of Alcoholism, 1964, 25, 240-247.

Schreiber, R. A. Effect of housing density on the incidence of audiogenic seizures in DBA/2J mice. Journal of Comparative and Physiological Psychology, 1971, 76, 300-304.

Scott, J. P. Agnostic behavior of mice and rats: A review. American Zoologist, 1966, 6, 683 .

Senault, B. Influence of isolation on the aggressive behavior induced by apomorphine in the rat. Psychopharmacologia, $1971,20,389-394$.

Shelley, H. P., \& Hoyenga, K. T. Sociability behavior and the social environment. Psychonomic Science, 1967, 8, 502-510

Thiessen, D. D., Lindzey, G., Blum, S. L., \& Wallace, P. Social interactions and scent marking in the Mongolian gerbil (Meriones unguiculatus). Journal of Comparative and Physiological Psychology, 1971, 77, 38-47.

Thiessen, D. D., Lindzey, G., \& Friend, H. C. Spontaneous seizures in the Mongolian gerbil. Psychonomic Science, 1968 , $11,227-228$.

Thiessen, D. D., Yahr, P., \& Owen, K. Regulatory mechanisms of territorial marking in the Mongolian gerbil. Journal of Comparative and Physiological Psychology, 1973, 82, 382-393.

Valzelli, L. Aggressive behaviour induced by isolation. In $S$. Garattini and E. B. Sigg (Eds.), Aggressive behaviour. Amsterdam: Excerpta Medica Foundation, 1969.

Wodzicki, K., \& Roberts, H. S. Influence of population density on the adrenal and body weights of the wild rabbit Orytolagus cuniculus $L$ : in New Zealand. New Zealand Journal of Science, 3, 103-120, In Psychological Abstracts, 1960.
(Received for publication June 27, 1974; revision received September 10, 1974.) 